\title{
Harnessing the value addition and nutraceutical potential of date fruits
}

\author{
Reema Rathore $\not$ \& Madhu Goyal \\ Department of Food and Nutrition, College of Home Science, SKRAU, Bikaner \\ Corresponding author: Reema Rathore, E-mail: reemarathore74@gmail.com
}

Copyright (O2016 Rathore \& Goyal, This is an open access article published under the terms of the Creative Commons Attribution License, which permits unrestricted use, distribution, and reproduction in any medium, provided the original work is properly cited.

Preferred citation for this article: Rathore R \& Goyal M. 2016. Harnessing the value addition and nutraceutical potential of date fruits. Journal of Agriculture and Ecology, 1: 3540; http://doi.org/10.53911/JAE.2016.1104.

\begin{abstract}
An investigation to harness the potentialities of date fruit to analyze Zahidi (Yellow coloured) and Khuneizi (Red coloured) varieties of date palm fruit was carried out. Date powder of fresh date fruits (doka stage) was developed in form of primary processed product. Value addition of date powder in terms of baked products was found to be organoleptically highly acceptable. The assessment regarding nutraceutical contents of date powder revealed a significant amount of flavonoids (88.26-92.00 CEQ/100g), total phenolic content (468.51$427.66 \mathrm{mg}$ GAE/100g) and total antioxidant activity by FRAP assay $(1227.89-1071.60 \mu \mathrm{mol}$ FRAP/100g). Khuneizi variety had significantly higher $(\mathrm{p}<.05)$ flavonoid, phenols and antioxidant activity as compared to Zahidi variety. A strong significant correlation was observed among flavonoids, phenols and antioxidant activity. Thus, date fruits in powdered form have a great potential in baking as well as functional food owing to its nutraceutical contents.
\end{abstract}

Key Words: Value addition, nutraceutical, date fruits

\section{Introduction}

Date palm (Phoenix dactylifera L.) is one of the oldest domesticated fruit trees in the world. It is mentioned in Quran and Bible that dates cure many disorders. Date palm belongs to family Palmaceae. (Jain et al. 2011). Dates are nutritious, assimilative and energy producing fruits. The botanical name of the date palm Phoenix dactylifera $L$. is presumably derived from a Phoenician name "Phoenix", which means date palm and "dactylifera" means 'date bearing', derived from a Greek word "daktulos" meaning a finger, illustrating the fruits form. (Chandra 1990). The date palm was known to ancient people as the "Tree of Life" and is probably one of the first fruit trees to be cultivated. It is an important and potential fruit crop of semi-arid 
and arid irrigated regions. Among various arid foods, date palm fruits are nutritious, assimilative, delicious and have high commercial potential in Rajasthan. Date fruits are eaten as fresh fruits (doka stage), dry dates (chuhhara) and soft dates (pind khajoor).

The protective effects of fruits against chronic diseases are attributed to bioactive nonnutrients secondary plant metabolites called phytochemicals. Phytochemicals have gained increased interest among several investigators including clinicians due to their nutraceutical values as antioxidant activity, cholesterol-lowering properties and other potential health benefits such as chemoprevention of cancer, prevention of diabetes and cardiovascular diseases. The interest in antioxidants has been increasing because of their high capacity in scavenging free radicals related to various diseases. (Khanavi et al. 2009). The antioxidant activity of dates may mainly be assigned to the presence of water-soluble compounds with potent free radical-scavenging effects, such as phenolic compounds (mainly cinnamic acids) and flavonoids (flavones, flavonols and flavanones). (Vayalil 2012) The present investigation was undertaken to harness the potentialities of date fruit to analyze Zahidi (Yellow coloured) and Khuneizi (Red coloured) varieties of date palm fruit with an aim to to develop date powder in form of primary processed product and standardize value added baked products with date powder. Besides, nutraceutical content of date powder in terms of flavonoids, total phenolic content and total antioxidant activity was assessed.

\section{Materials and methods}

Khuneizi and Zahidi varieties grown at Date Palm Research Centre, S.K.R.A.U., Bikaner were procured in their doka stage in the season of their availability i.e. July-September. The date pieces were processed into dried chunk form to serve as base material for the development of various value added products. Dried fruit chunks can be preserved for longer period and it can be powdered before being used in different value added products. The doka stage fruits were washed thoroughly and blanched by dipping in boiling water for two minutes and immediately cooled thereafter in cold water. The blanching process was standardized prior to the experiment. The fruits were dried through shade drying and in air circulating oven to a constant weight. The drying process was continued till the date fruits became brittle. These were stored in cool and dry place. Dried shreds were oven dried and powdered in an electrically operated grinder to a fine powder. Date powder of both varieties was organoleptically evaluated for their colour, appearance, texture, flavour, taste and overall acceptability. Thereafter, value added products like Date Muffins and Date Biscuits were prepared and organoleptically evaluated for their colour, appearance, texture, flavour, taste and overall acceptability.

Crude extract of each sample was prepared. Water-methanol solution was chosen as extracting solvent as it is the most frequently used solvent antioxidant extraction. (Manach et al, 2004) (Fig.1). Flavonoids: Aluminium chloride method was used for flavonoid determination. (Kaur, 2011) The absorbance was noted at 510nm using UV-Visible spectrophotometer. The amount of total flavonoid was determined with the Quercetin reagent and the flavonoid was expressed as $\mathrm{mg} / \mathrm{g}$ Quercetin equivalent. Total phenolic content: The 
total phenol content of extracts was estimated colorimetrically with the Folin-Ciocalteu method (Manach et al, 2004) based on the procedure as suggested by Waterhouse, 2002 with some modifications. The absorbance was measured at $765 \mathrm{~nm}$ in a spectrophotometer (Systronics 2203, Double beam spectrophotometer). Gallic acid was used as a standard compound and the concentration of total phenolic compounds in the extract was determined as milligram of gallic acid equivalent.

Fig. 1. Flow chart for preparation of methanolic extract from sample

Twenty grams of powdered sample $+200 \mathrm{ml}$ of $80 \%(\mathrm{v} / \mathrm{v})$ methanol

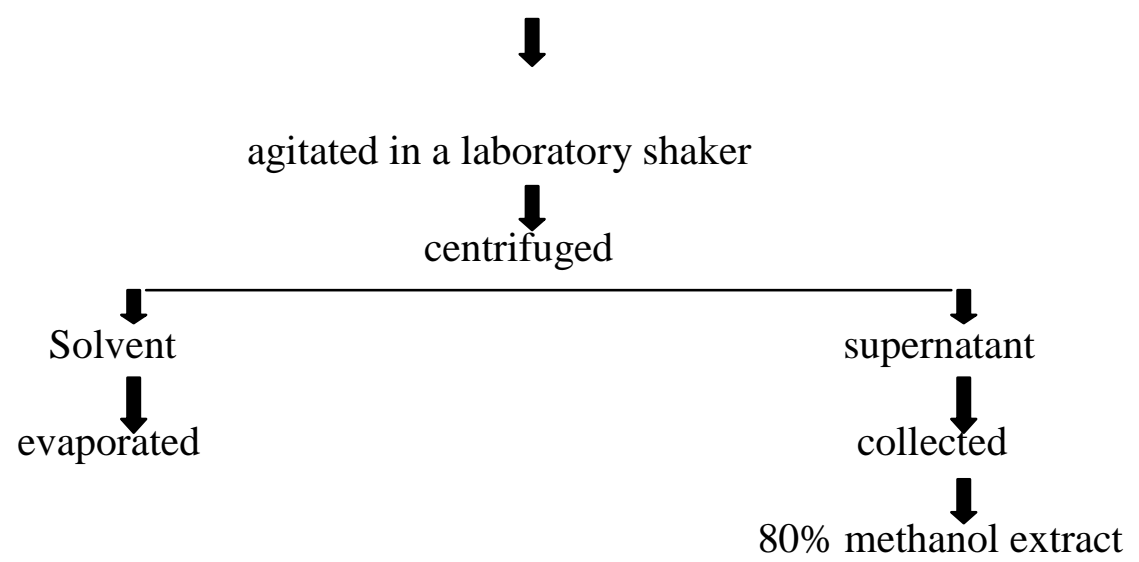

Total antioxidant capacity by FRAP assay (Ferric ion reducing antioxidant power): This assay was carried out as described by Biglari et al. 2008, using a modified method of Benzie and Strain (1999). This method measures the ability of a compound to reduce ferric ion to ferrous ion.

Statistical Analysis: The data for nutraceutical assessment was analyzed by using SPSS statistics (Ver. 20) software to find out significance of the results. The results are expressed as mean \pm SD. 'T-test' was used to compare both the selected varieties. Pearson's correlation coefficient between the antioxidant activity, total phenolics, and flavonoid content of date palm fruit extracts were established.

\section{Results and Discussion}

During the present study the fresh date fruits in the form of pieces were subjected to primary processing. The resultant primary processed products were dried chunks from date pieces. The primary processed product (powder) from different forms of date fruits (date pieces) were "liked very much" on Hedonic rating scale. It is important to note that acceptability scores for both the varieties were at par and the difference in the mean scores of all the 
sensory attributes was non significant $(\mathrm{p}<05)$. The results regarding Total Flavonoid Content (TFC) in fresh date fruit and primary processed products are presented in Table 1.

Table 1. Organoleptic acceptability of primary processed products of date fruits

\begin{tabular}{|c|c|c|c|c|c|c|c|}
\hline \multirow{3}{*}{$\begin{array}{l}\text { Primary } \\
\text { processed } \\
\text { products }\end{array}$} & \multicolumn{7}{|c|}{ Values $^{1}$ of sensory characteristics on 9 point hedonic rating scale $\left(\right.$ Mean $\left.\pm \mathrm{SD}^{2}\right)$} \\
\hline & Variety & Colour & Appearance & Flavour & Texture & Taste & Overall \\
\hline & $K$ & $8.60 \pm 0.39$ & $8.50 \pm 0.47$ & $8.05 \pm 0.27$ & $8.50 \pm 0.33$ & $8.70 \pm 0.26$ & $8.47 \pm 0.16$ \\
\hline & $Z$ & $8.40 \pm 0.38$ & $8.15 \pm 0.53$ & $8.05 \pm 0.50$ & $8.55 \pm 0.28$ & $8.65 \pm 0.30$ & $8.36 \pm 0.17$ \\
\hline & t value & 1.159 & 1.561 & 0.000 & -0.361 & 0.397 & 1.465 \\
\hline
\end{tabular}

$K=$ Khuneizi variety, $Z=$ Zahidi variety, ${ }^{1}$ Values are mean $(\mathrm{n}=10) \pm \mathrm{SD}$ scores

A perusal of data showed that date fruits contained 4.67 and $3.26 \mathrm{mg} / 100 \mathrm{~g}$ flavonoids in both khuneizi and zahidi varieties respectively. The difference was noted to be significant at $1 \%$ level of significance. The results are in close conformity with those reported earlier by Biglari et al. 2008 and Zineb et al. 2012. Al Farsi et al (2005) found total flavonoid content (TFC) of date varying from $0.010 \mathrm{mg}$ to $0.38 \mathrm{mg} / 100 \mathrm{~g}$ fresh weight as quercetin equivalents $(\mathrm{QE})$. Likewise, the values of the flavonoid content of date fruits analysed during present study was lower than earlier reports which claimed much higher total flavanoid content i.e. in between $167 \mathrm{mg}$ to $343 \mathrm{mg}$ GAE/100 $\mathrm{g}$ of fresh Omani dates. The reason behind such remarkable difference in the flavonoid content could be due to variation in method of analysis, plants related factors such as variety, maturity, season, geographic origin, fertilizer, soil type, storage conditions and amount of sunlight received by the plants.

It was observed that the total phenolic content in fresh date fruits of zahidi and khuneizi variety were found to be in the range of 212.26 and $224.09 \mathrm{mg}$ GAE/100 $\mathrm{g}$ respectively. (Table 1) Present phenolic contents of fresh date fruits were almost in line with findings of $\mathrm{Al}$ Farsi et al (2005) who observed total phenolics content value in between 172.0 and $246.0 \mathrm{mg}$ GAE /100 g fresh weight for some Omani date fruits. Almost similar results of the FolinCiocalteu total phenol assay have also been reported by Khanavi et al (2009) for date fruit extracts of different varieties. The total antioxidant activity exhibited by fresh date fruits was 39.84- $44.68 \%$ by zahidi and khuneizi varieties respectively (Table 1). Date fruit's extract were tested for DPPH radical scavenging activity. However higher antioxidant power to the extent of $56.61 \%$ was reported by Khanavi et al (2009). The strength of the relationship between variables was measured using the Pearson correlation coefficient $(r)$ and the significance of the relationship was expressed by probability levels $(p<0.01)$. Table 2 clearly unfurls that a significant correlation existed among flavonoids, total phenolic content and 
antioxidant activity of date fruits during the present study. Correlation was significant at 0.01 levels (2-tailed).

Table 2. Mean nutraceutical contents of date fruits

\begin{tabular}{|c|c|c|c|}
\hline \multirow{2}{*}{$\begin{array}{ll}\text { Date } \quad \text { Fruits } \\
\text { Variety }\end{array}$} & \multicolumn{3}{|c|}{ Mean Nutraceuticals Contents } \\
\hline & $\begin{array}{c}\text { Flavanoids } \\
\text { mg CEQ/100g }\end{array}$ & $\begin{array}{c}\text { Total Phenolic Content mg } \\
\text { GAE } / 100 \mathrm{~g}\end{array}$ & $\begin{array}{c}\text { DPPH assay } \\
(\%)\end{array}$ \\
\hline Khuneizi & $4.67 \pm 0.48$ & $224.53 \pm 1.68$ & $44.48 \pm 2.38$ \\
\hline Zahidi & $3.26 \pm 0.54$ & $212.53 \pm 2.24$ & $39.43 \pm 1.07$ \\
\hline t-value & $3.380^{*}$ & $7.422 * *$ & $2.979 * *$ \\
\hline
\end{tabular}

Values are mean $(\mathrm{n}=3) \pm$ SD scores, $\quad \mathrm{p}<0.05$ with superscripts* significantly different at $95 \%, \mathrm{p}<0.01$ with superscripts** significantly different at $99 \%$

Table 3. Correlation coefficient matrix/ value for flavonoids, total phenolic content and antioxidant activity by DPPH assay.

\begin{tabular}{lccc}
\hline Parameters & Flavonoids & phenols & DPPH \\
\hline Flavonoids & 1 & & \\
phenols & $.981^{* *}$ & 1 & \\
DPPH & $.869^{* *}$ & $.937^{* *}$ & 1 \\
\hline
\end{tabular}

** Correlation is significant at the 0.01 level (2-tailed)

A positive relationship existed between antioxidant activity and phenolic content for dates which justifies that antioxidant activities have a strong linear relationship with flavonoids and total phenolic contents. (Mansouri et al. 2008; Allaith 2008; Biglari et al. 2008; Odeh et al. 2014). Date fruit and its products are rich in toal phenolic content, flavanoids and shows significant antioxidant activity which overall explains their potency of being a power-packed fruit. Dates serve as a good source of natural antioxidants and could potentially be considered as functional food or ingredient having potential health benefits.

\section{References}

Al-Farsi M, Alasalvar C, Morris A, Baron M \& Shahidi F. 2005.Comparison of antioxidant activity, anthocyanins, carotenoids, and phenolics of three native fresh and sun-dried date (Phoenix dactylifera L.) varieties grown in Oman. Journal of Agricultural and Food Chemistry, 53: 7592-7599.

Al-Farsi MA \& Lee CY. 2008. Nutritional and functional properties of dates: a review. Critical Reviews in Food Science and Nutrition, 48: 877-887.

Allaith AAA. 2008. Antioxidant activity of Bahraini date palm (Phoenix dactylifera L.) fruit of various cultivars. International Journal of Food Science \& Technology, 43(6): 1033-1040.

Biglari F, AlKarkhi AFM \& Easa AM. 2008. Antioxidant activity and phenolic content of various date palm (Phoenix dactylifera L.) fruits from Iran. Food Chemistry, 107:1636-1641. 
Chandra TR. 1990. Date palm.- Arid Fruit Research. In: Textbook of temperate fruits. ICAR, New Delhi. pp: 163-165.

Jain SM, Al-Khayri JM \& Johnson DV. 2011. (Eds.). Date palm biotechnology. Springer Science \& Business Media: 2011.

Kaur C. 2011. Biotechnological approach for the enhanced production of nutraceuticals in fruits and vegetables of arid zone. Training Manual by CIAH, Beechwal, Bikaner. pp: 181-187.

Khanavi M, Saghari Z, Mohammadirad A, Khademi R \& Abdollahi M. 2009. Comparison of antioxidant activity and total phenols of some date varieties. DARU Journal of Pharmaceutical Sciences, 17(2):104-108.

Manach C, Scalbert A, Morand C, Rémésy C \& Jiménez L. 2004. Polyphenols: food sources and bioavailability. The American Journal of Clinical Nutrition, 79(5): 727-747.

Mansouri A, Embarek G, Kokkalou E \& Kefalas P. 2005. Phenolic profile and antioxidant activity of the Algerian ripe date palm fruit (Phoenix dactylifera). Food Chemistry, 89: 411-420.

Odeh, I, Al-Rimawi, F, Abbadi, J, Obeyat, L, Qabbajeh, M \& Hroub, A. 2014. Effect of harvesting date and variety of date palm on antioxidant capacity, phenolic and flavonoid content of date palm (Phoenix dactylifera). Journal of Food and Nutrition Research, 2(8): 499-505.

Vayalil PK. 2012. Date fruits (Phoenix dactylifera Linn): an emerging medicinal food. Critical reviews in food science and nutrition, 52(3): 249-271.

Waterhouse AL.2002. Determination of total phenolics. Current protocols in food analytical chemistry, 11.1.1.11.1.8.

Zineb G, Boukouada M, Djeridane A, Saidi M \& Yousfi M. 2012. Screening of antioxidant activity and phenolic compounds of various date palm (Phoenix dactylifera) fruits from Algeria. Mediterranean .Journal of Nutrition and Metabolism, 5(2): 119-126. 